\title{
Training in Surgery, Matthew D. Gardiner and Neil R. Borely (eds)
}

\author{
Oxford University Press, Inc., USA, 2009, 464 pp, paperback, ISBN-10: 0199204756, \\ $\$ 79.95$ (amazon.com)
}

\author{
Danny Rosin
}

Published online: 16 September 2009

(c) Société Internationale de Chirurgie 2009

This textbook, edited by Matthew Gardiner, a research fellow in plastic surgery from London, and Neil Borely, a colorectal surgeon from Cheltenham, contains more than 400 pages arranged in a novel format. It's a UK-centered book designed for UK surgical trainees, but as surgery is a universal profession, most of its content could be relevant for a surgical trainee anywhere in the world. However, it was created as a reference book based on the web-based Intercollegiate Surgical Curriculum Programme, a UK program approved for all surgical trainees by the Postgraduate Medical Education and Training Board.

Contrary to classical textbooks in surgery, so well known to practicing surgeons, this book was formed for the "Twitter (not to say PowerPoint) generation." The idea was: no more well-phrased paragraphs, no more long and extensive chapters covering every aspect of the title subject. Everything we need to know can be found on the web anyway, so why bother with boring texts when what we need is to convey some facts and their clinical relevance? Let's create a format that will cover all the pointed subjects of the curriculum, allocate two pages to each-whether hemorrhoids, liver and spleen disorders, microbiology, colon cancer, or nutrition - and add some boxes to cover the relevant clinical and technical skills required by the curriculum. Then let's illustrate each chapter (main subject) with some case-based discussions.

The final product is indeed well organized, and the most important subjects the surgical trainee has to learn are covered. I tend to believe most students and residents nowadays like such a format: easy to browse, easy to memorize, useful to prepare for a specific rotation or an examination. The step-by-step description of some procedures makes it easy to prepare before scrubbing into a case. But, as such, there are not a few surgical handbooks available providing this kind of stenographic description of our wide and extensive profession. The advantage of this book, for the UK trainee, may be its conformity with the official curriculum; otherwise it does not provide a breakthrough in methodology.

The book covers all surgical subspecialties, and the overall space dedicated to general surgery is rather limited (three chapters of the 15 in the book, with some subjects covered in other chapters, like Emergency Surgery). This allocation may be appropriate to a medical student who is briefly exposed to the surgical profession and its subspecialties, but not to a surgical resident, who needs to know much more about the main field of interest. Moreover, as a handbook, this book is somewhat "too big" and heavy, printed in small font that is not easy to read (am I getting old?). As a textbook, it is too basic and shallow (complications of laparoscopic cholecystectomy are covered by only 2 points in 3 lines), and I find it difficult to accept that the classical textbook is dead, to be replaced by this "grocery list" format.

So who should or would purchase this book other than our young colleagues undergoing their basic surgical training somewhere in the British Isles? To tell you the truth-I don't know!

D. Rosin $(\square)$

Department of Surgery B, Sheba Medical Center,

Tel Hashomer, Israel

e-mail: drosin@mac.com 